\title{
Knowing and Using 4-H Curricula ${ }^{1}$
}

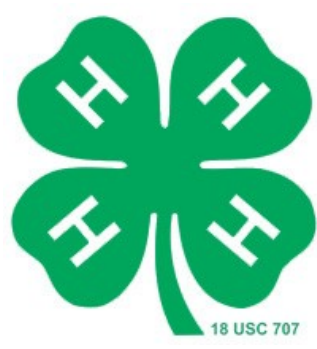

Marilyn N. Norman and Joy C. Jordan ${ }^{2}$

In planning experiences for youth that target life skills and help youth become aware of the concepts they have learned from those experiences, it is important to remember that young people have different learning styles, and approach or respond to a learning activity differently. Adults will have the most success in appealing to youth if there are a wide variety of activities with opportunities for all learning styles.

Briefly, plan to include opportunities for those who prefer to learn

- by reading (print learners)

- by hearing: sound and voice (auditory learners)

- by touching or manipulating objects. (tactile learners)

- from what they see: color, shape and form. (visual learners)

- by using their bodies: rhythm and movement. (kinesthetic learners)

- by working in groups (interactive learners)

- by working independently (independent learners)
- by observing others do something

(observational learners)

- with a lot of direction, or

- by figuring things out with little instruction.

Effective youth development professionals incorporate many activities into their programs that collectively appeal to all of these learning styles. In addition, they facilitate the processing of those activities to direct the learning toward the targeted goal.

One of the advantages 4-H has to offer the youth development field is the vast amount of written resources available for youth at very little cost. The rigor of the national review system assures the user of high quality, age appropriate, content accurate, user-friendly products. Adult volunteers and faculty have access to these curricula. County 4-H faculty need to be aware of all of the materials available to support 4-H and 4-H partners in the county. Of particular interest will be Cooperative Curriculum System (CCS) and state produced curricula, both for sale and listed at the state $4-\mathrm{H}$ website.

\footnotetext{
1 This document is 4-H S FS101.8, one of a series of the Florida 4-H Program, Florida Cooperative Extension Service, Institute of Food and Agricultural Sciences, University of Florida. This material is based upon work supported by the Cooperative Research, Education, and Extension Service, US Department of Agriculture, and K-State Research and Extension, Kansas State University, under special project number 99-EYAR-1-0747. This 4-H 101 Handbook was developed by the 4-H 101 Design Team chaired by Andrea Hutson, USDA/Army Youth Development Project, CSREES/Virginia Tech University. It was adapted for Florida by Marilyn N. Norman and Joy C. Jordan, State 4-H Program. Published May 2006. Please visit the 4-H Website at http://4h.ifas.ufl.edu

2

2 Marilyn Norman, Associate Professor in Family Youth and Community Sciences, and State 4-H Program Leader, and Joy C. Jordan, Associate Professor in Family, Youth and Community Sciences, Institute of Food and Agricultural Sciences, University of Florida, Gainesville.
} 